Article

\title{
Enhanced Mechanical and Antibacterial Properties of Nanocomposites Based on Poly(vinyl Alcohol) and Biopolymer-Derived Reduced Graphene Oxide
}

\author{
Beom-Gon Cho ${ }^{+}\left(\mathbb{D}\right.$, Shalik Ram Joshi ${ }^{\dagger}$, Seongjin Lee, Shin-Kwan Kim, Young-Bin Park * and Gun-Ho Kim * \\ Department of Mechanical Engineering, Ulsan National Institute of Science and Technology, UNIST-gil 50 \\ Ulju-gun, Ulsan 44919, Korea; chogony1@unist.ac.kr (B.-G.C.); shalik@unist.ac.kr (S.R.J.); grant@unist.ac.kr (S.L.); \\ skim@unist.ac.kr (S.-K.K.) \\ * Correspondence: ypark@unist.ac.kr (Y.-B.P.); gunhokim@unist.ac.kr (G.-H.K.); Tel.: +82-52-217-2314 (Y-B.P.); \\ +82-52-217-2413 (G.-H.K.) \\ † These authors contributed equally to this work.
}

check for updates

Citation: Cho, B.-G.; Joshi, S.R.; Lee, S.; Kim, S.-K.; Park, Y.-B.; Kim, G.-H. Enhanced Mechanical and Antibacterial Properties of Nanocomposites Based on Poly(vinyl Alcohol) and Biopolymer-Derived Reduced Graphene Oxide. Polymers 2021, 13, 615. https://doi.org/ $10.3390 /$ polym 13040615

Academic Editor: Thang Quyet Tran

Received: 8 February 2021

Accepted: 16 February 2021

Published: 18 February 2021

Publisher's Note: MDPI stays neutral with regard to jurisdictional claims in published maps and institutional affiliations.

Copyright: (C) 2021 by the authors Licensee MDPI, Basel, Switzerland. This article is an open access article distributed under the terms and conditions of the Creative Commons Attribution (CC BY) license (https:// creativecommons.org/licenses/by/ $4.0 /)$

\begin{abstract}
Functionalized graphene-polymer nanocomposites have gained significant attention for their enhanced mechanical, thermal, and antibacterial properties, but the requirement of multi-step processes or hazardous reducing agents to functionalize graphene limits their current applications. Here, we present a single-step synthesis of thermally reduced graphene oxide ( $\operatorname{TrGO}$ ) based on shellac, which is a low-cost biopolymer that can be employed to produce poly(vinyl alcohol) (PVA)/TrGO nanocomposites (PVA-TrGO). The concentration of TrGO varied from 0.1 to $2.0 \mathrm{wt} . \%$, and the critical concentration of homogeneous TrGO dispersion was observed to be $1.5 \mathrm{wt} . \%$, below which strong interfacial molecular interactions between the TrGO and the PVA matrix resulted in improved thermal and mechanical properties. At $1.5 \mathrm{wt}$ \% filler loading, the tensile strength and modulus of the PVATrGO nanocomposite were increased by $98.7 \%$ and $97.4 \%$, respectively, while the storage modulus was increased by $69 \%$. Furthermore, the nanocomposite was $96 \%$ more effective in preventing bacterial colonization relative to the neat PVA matrix. The present findings indicate that TrGO can be considered a promising material for potential applications in biomedical devices.
\end{abstract}

Keywords: nanocomposites; shellac; poly(vinyl alcohol); thermally reduced graphene oxide; mechanical properties; thermal stability; antibacterial activity

\section{Introduction}

Poly(vinyl alcohol) (PVA) is a widely used commercial polymer owing to its high transparency, hydrophilicity, and adhesive properties [1-4]. Furthermore, its strong oxygen barrier capabilities and mechanical and biodegradable properties promote the application of PVA in fiber manufacturing, food packaging, and biomedicine [5-9]. However, the mechanical and electrical properties of PVA are negatively affected by the poor dewetting properties of this polymer $[10,11]$, and its solubility, viscosity, and film strength may also differ depending on the degree of saponification [12]. To improve the aforementioned properties, various inorganic nanomaterials, such as clay [13], carbon nanotubes [14], and metal oxide nanoparticles [15], have been incorporated into a PVA matrix. However, poor dispersion and significant agglomeration of these nanofillers in the PVA matrix limit the improvement of the physical properties far below the expected level. Hence, it is essential to synthesize PVA nanocomposites with homogeneously dispersed fillers, which can significantly improve PVA physicochemical properties.

Owing to its high thermal, electrical, and mechanical properties, graphene has also been considered a potential filler for the synthesis of lightweight polymer nanocomposites [16]. However, the current manufacturing methods are not appropriate for producing high-quality graphene at the industrial scale [17]. Furthermore, owing to the presence 
of strong van der Waals forces, the obtained graphene flakes exhibit poor dispersion in the polymer matrix $[18,19]$. On the contrary, graphene oxide (GO) exhibits homogeneous dispersion properties due to the presence of oxygen-containing functional groups that establish strong interactions with the hydroxyl groups of the polymer matrix [20]. This homogeneous dispersion of GO at intermolecular level helps the efficient load transfer between the filler and the PVA matrix, resulting in significant enhancement of the physicochemical properties of the nanocomposites, even at low filler concentrations. However, GO is electrically insulating and thermally unstable; therefore, it needs to be reduced to restore the electrical and thermal properties [21]. During the preparation of polymer nanocomposites, the direct use of reduced graphene oxide (rGO) fillers is preferred to optimize the industrial synthesis and application of graphene-based polymer composites. However, the rGO chemical reduction process is time-consuming and requires the use of several toxic reagents that induce high structural disorder, which results in reduced mechanical properties of the polymer nanocomposites [22,23].

Shellac, a low-cost natural biopolymer, has been widely used in organic biomedical devices because of its excellent biocompatibility [24,25]. The long aliphatic carbon $(C-C)$ backbone and a relatively lower thermal decomposition temperature of shellac provide an opportunity for more efficient graphitization than other synthetic polymers [26]. Earlier reports have shown that shellac-derived GO can be used as an active material in the fabrication of sensors and in photocatalytic applications [27-29]. Furthermore, it exhibits superior adhesion, due to the presence of oxygen-containing functional groups that form strong covalent bonds with the surface. This brought about a significant improvement in the interlaminar shear and flexural strength of GO [30]. These advantages of shellacderived GO suggest its potential as a cost-effective polymer composite additive to improve the antibacterial and mechanical properties of materials.

The present study demonstrates the effect of various concentrations of shellac-derived thermally reduced graphene oxide ( $\operatorname{Tr} \mathrm{GO}$ ) on the thermal, mechanical, and antibacterial properties of PVA-TrGO nanocomposites. TrGO nanosheets were synthesized by a singlestep thermal reduction process, in which homogeneous PVA-TrGO nanocomposites were produced by a water-based solution casting technique. The chemical and structural properties of PVA-TrGO nanocomposites were investigated using Fourier-transform infrared (FT-IR) spectroscopy and wide-angle X-ray diffraction (WAXD). Furthermore, the thermal, mechanical, and antibacterial properties of PVA-TrGO nanocomposites were investigated using differential scanning calorimetry (DSC), thermogravimetric analysis (TGA), tensile test, dynamic mechanical analysis (DMA), and Gram-negative Escherichia coli (ATCC 25922), respectively. It is expected that this study will help elucidate the effect of the nano-and microscale TrGO reinforcement of a PVA matrix and provide a viable method for the synthesis of polymer nanocomposites used in medical applications requiring improved mechanical and antibacterial properties.

\section{Materials and Methods}

\subsection{Materials}

A $99 \%$ hydrolyzed PVA $\left(\mathrm{M}_{\mathrm{w}}=31,000-50,000\right)$ was purchased from Sigma-Aldrich (St. Louis, MO, USA). Shellac flakes were purchased from Shellac Shack (Port Orford, OR, USA). Isopropanol (IPA; 99.5\%) was purchased from Sigma-Aldrich (St. Louis, MO, USA).

\subsection{Fabrication of $P V A-T r G O$ Films}

The PVA-TrGO nanocomposites were synthesized using a solution casting technique. Shellac was used as a carbon precursor to synthesize TrGO nanosheets via a single-step thermal reduction process. First, ball milling (planetary ball milling PM100 (Retsch), Hamburg, Germany) of shellac flakes (10 g) was carried out in a stainless-steel jar while agitating at a revolution speed of $200 \mathrm{rpm}$ and an autorotation speed of $250 \mathrm{rpm}$. Ball milling running and cooling were performed for $5 \mathrm{~min}$, to complete one milling cycle. A total of 30 milling cycles was performed, corresponding to a milling time of $150 \mathrm{~min}$. 
Fourier Transform Infrared (FT-IR) spectra for shellac powder were obtained to observe any impurities during the ball milling process, as shown in Figure S1. The resultant powder was then placed into a tube furnace (Kejiafurnace, Zhengzhou, China) for thermal reduction. The ramping rate of the tube furnace was set to $3{ }^{\circ} \mathrm{C} / \mathrm{min}$ and maintained at $900{ }^{\circ} \mathrm{C}$ for 30 min under a vacuum of 0.12 mbar.

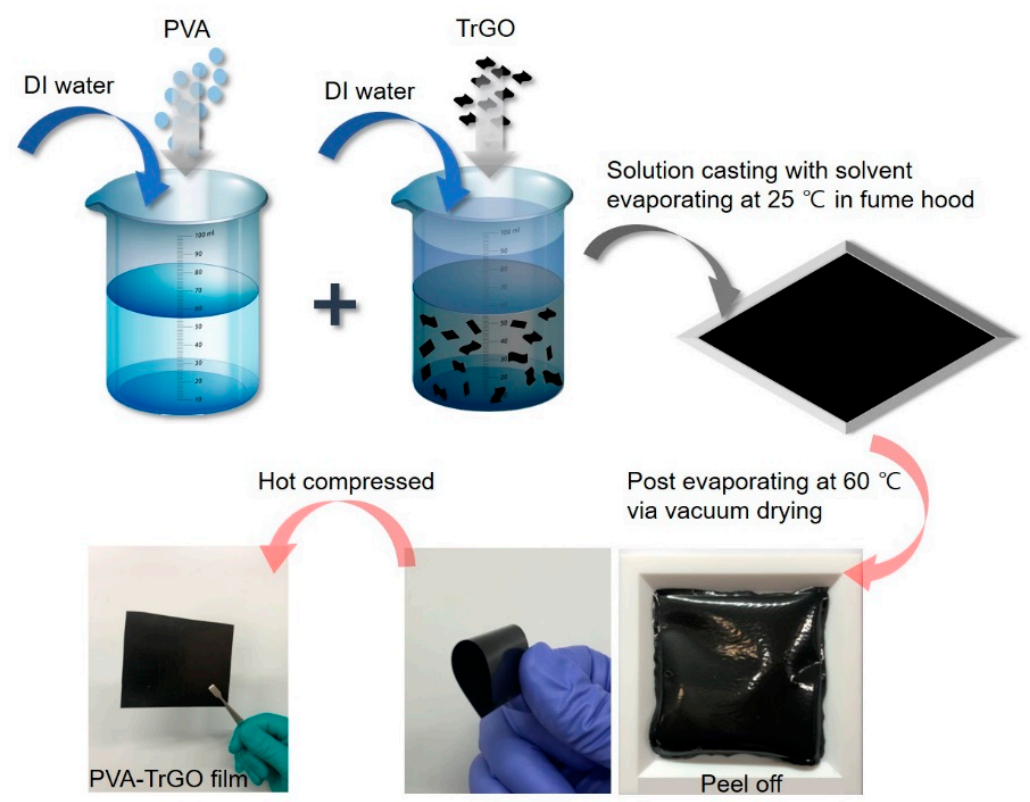

Figure 1. Schematic representation for the synthesis of poly(vinyl alcohol (PVA)-thermally reduced graphene oxide (TrGO) nanocomposite films.

PVA was dried at $90^{\circ} \mathrm{C}$ for $24 \mathrm{~h}$ in a vacuum drying oven (Thermo Fisher Scientific, Waltham, MA, USA). Three grams of dried PVA was dissolved in $10 \mathrm{~mL}$ of distilled (DI) water at $90{ }^{\circ} \mathrm{C}$ at a stirring rate of $300 \mathrm{rpm}$. Various concentrations $(0.1 \mathrm{wt} . \%, 0.5 \mathrm{wt} . \%$, $1 \mathrm{wt} . \%, 1.5 \mathrm{wt} . \%$, and $2 \mathrm{wt} . \%$ ) of TrGO were dispersed in $10 \mathrm{~mL}$ of DI water by ultrasonication (Branson5800, Branson Ultrasonic Corp., Brookfield, CT, USA) for $1 \mathrm{~h}$. The dispersion was placed in a homogenizer (T 18, IKA, Staufen, Germany) for $10 \mathrm{~min}$, followed by a bath sonication process for another $60 \mathrm{~min}$. The resultant TrGO suspension was then added to the PVA solution and mixed by bath sonication for $30 \mathrm{~min}$. After homogenization, the mixture was poured into a Teflon mold and dried at $25^{\circ} \mathrm{C}$ for $1 \mathrm{~d}$ in a fume hood (Nara fume hood, Flowmaster, Seoul, Korea) until solidified, as shown in Figure 1. The Teflon mold was kept at $60{ }^{\circ} \mathrm{C}$ in a vacuum oven (OV11, JEIO Tech, Daejeon, Korea) until the mass of the sample was constant. Finally, the resultant film was peeled off from the mold and compressed for $10 \mathrm{~min}$ using a hot press technique to eliminate voids. The resulting film surface was smooth and had an average thickness of $180 \mu \mathrm{m}$.

\subsection{Characterization}

\subsubsection{Thermally Reduced Graphene Oxide}

Raman spectra of shellac-derived TrGO flakes were acquired in backscattering mode using an ultrahigh-throughput spectrometer (alpha300R, WiTec, Ulm, Germany). X-ray diffraction (XRD) measurements were performed using a Bruker D8 Advance diffractometer (Bruker, Billerica, MA, USA) with $\mathrm{Cu} \mathrm{K} \alpha$ radiation $(0.154 \mathrm{~nm})$. The crystallinity and elemental mapping were investigated using high-resolution transmission electron microscopy (HR-TEM, JEOL Ltd., Tokyo, Japan) and high-angle annular dark-field scanning TEM (HAADF-STEM) fitted with an aberration corrector (CEOS GmbH, Heidelberg, Germany). A JEOL JEM-2100F electron microscope (JEOL Ltd., Tokyo, Japan) operating at $200 \mathrm{kV}$ was used to perform the HR-TEM and HAADF-STEM. The chemical analysis was performed using X-ray photoelectron spectroscopy (XPS) (Thermo Fisher Scientific, 
Waltham, MA, USA). The system was equipped with a double-focusing hemispherical analyzer and a monochromatic $\mathrm{Al} \mathrm{K} \alpha$ source $(1486.6 \mathrm{eV})$ (Thermo Fisher Scientific, Waltham, MA, USA). The vacuum of the main chamber was maintained at $1 \times 10^{-10}$ mbar during the entire measurement. XPSPeak41 software developed by Raymund Kwok was used for the deconvolution of the high-resolution XPS spectra.

\subsubsection{PVA-TrGO Nanocomposites}

FTIR spectra of the PVA-TrGO nanocomposites were obtained using Varian 670-IR (Agilent Technologies, Santa Clara, CA, USA) to investigate the formation of hydrogen bonds between PVA and TrGO with different TrGO concentrations. The crystallinity of the nanocomposites was analyzed using wide-angle X-ray diffraction (WAXD). WAXD patterns of the PVA-TrGO nanocomposites were obtained in the 20 range $8-40^{\circ}$ at a rate of $2^{\circ} / \mathrm{min}$, using a high-resolution X-ray diffractometer (D8 Advance, Bruker, Billerica, MA, USA) with $\mathrm{Cu} \mathrm{K} \alpha$ target. The crystallinity index $(C I)$ of the film was calculated using the following equation:

$$
C I=\frac{A_{c}}{A_{c}+A_{a}}
$$

where $A_{c}$ is the integrated area of the crystalline peaks, and $A_{a}$ is the integrated area under the amorphous halo. The thermal studies were conducted using DSC (Q200, TA Instruments, New Castle, DE, USA) and TGA (Q500, TA Instruments, New Castle, DE, USA). During the DSC measurement, nitrogen gas was purged into the chamber at a flow rate of $50 \mathrm{~mL} / \mathrm{min}$. The crystallization isotherms of the samples were investigated by completing a heating-cooling cycle where the samples were first heated from $30{ }^{\circ} \mathrm{C}$ to $250{ }^{\circ} \mathrm{C}$ at a ramping rate of $10^{\circ} \mathrm{C} / \mathrm{min}$ and then cooled to $0{ }^{\circ} \mathrm{C}$ at a ramping rate of $10{ }^{\circ} \mathrm{C} / \mathrm{min}$. The third scan was performed from $0{ }^{\circ} \mathrm{C}$ to $250{ }^{\circ} \mathrm{C}$ at a rate of $10{ }^{\circ} \mathrm{C} / \mathrm{min}$, during which the melting endotherms were identified. The degree of crystallinity $\left(X_{\mathcal{C}}\right)$ was calculated as follows:

$$
X_{c}=\frac{\Delta H_{m}}{\Delta H_{m}^{0}} \times 100 \%
$$

where $\Delta H_{m}$ and $\Delta H_{m}^{0}(138.7 \mathrm{~J} / \mathrm{g})$ are the enthalpies of the nanocomposite and pure PVA matrix, respectively. The thermal stability of the PVA-TrGO nanocomposites with varying TrGO concentrations was investigated using TGA in a nitrogen environment. The samples were annealed from $30{ }^{\circ} \mathrm{C}$ to $800{ }^{\circ} \mathrm{C}$ at a ramping rate of $10^{\circ} \mathrm{C} / \mathrm{min}$. The morphologies and dispersion states of the nanocomposites were investigated by field-emission scanning electron microscopy (FE-SEM) (FEI Nova Nano 230, New York, NY, USA) at 10 kV accelerating voltage. Cross-sectional surface analysis was performed by fracturing the samples in liquid nitrogen and coating them in a platinum layer. The tensile properties of the nanocomposites, with sample dimensions of $5 \mathrm{~mm} \times 30 \mathrm{~mm} \times 0.18 \mathrm{~mm}$, were analyzed using a universal test machine (UTM, Shimadzu, Kyoto, Japan) with a crosshead speed of $1 \mathrm{~mm} / \mathrm{min}$, in accordance with the ASTM D882 standard. The dynamic mechanical behavior of the composites was analyzed using dynamic mechanical analysis equipment (Q800, TA Instruments, DE, USA), in accordance with the ASTM D4065 standard. The measurements were carried out in multi-frequency strain mode using a tension film clamp within the temperature range of $40^{\circ} \mathrm{C}-150{ }^{\circ} \mathrm{C}$, at a heating rate of $3{ }^{\circ} \mathrm{C} / \mathrm{min}$ and a frequency of $1 \mathrm{~Hz}$.

The antibacterial activities of the nanocomposites were investigated using Gramnegative E. coli (ATCC 25922). The bacterial strain of E. coli (ATCC ${ }^{\circledR} 25922^{\mathrm{TM}}$ ) from a stock was streaked onto a Luria-Bertani (LB) agar plate (Difco Generic LABWARE, Cadorago, Italy) and incubated at $37{ }^{\circ} \mathrm{C}$ with $5 \% \mathrm{CO}_{2}$. After $18 \mathrm{~h}$ of incubation, the isolated colonies that appeared were inoculated into $10 \mathrm{~mL}$ of LB medium (Difco Generic LABWARE, Cadorago, Italy ), incubated at $37^{\circ} \mathrm{C}$, and stirred at $150 \mathrm{rpm}$ until the logarithmic growth phase was achieved with a concentration in the range of $10^{7}-10^{8}$ colony-forming units (CFU)/mL. Approximately $100 \mu \mathrm{L}$, at a concentration of $10^{8} \mathrm{CFU} / \mathrm{mL}$, of the bacterial suspension was added to the surface of the PVA-TrGO nanocomposites. Bacterial cells 
were dispensed on empty Petri dishes as the control. After the treatment, the bacterial solution on the nanocomposite surface was successively diluted $10^{1}-10^{6}$ fold in sterile phosphate-buffered saline (PBS) and cultured on LB agar plates. The cultured plates were incubated at $37^{\circ} \mathrm{C}$ with $5 \% \mathrm{CO}_{2}$ for $18 \mathrm{~h}$. The experiment was performed in triplicate for accurate statistical analysis.

\section{Results and Discussion}

\subsection{Structural and Chemical Characterization of Shellac-Derived $\operatorname{Tr} G O$}

A structural analysis of TrGO was performed using XRD and Raman spectroscopy, and the results are shown in Figure 2. The Raman spectra of TrGO displayed three main peaks: a D-band $\left(\sim 1345 \mathrm{~cm}^{-1}\right)$, a G-band $\left(\sim 1592 \mathrm{~cm}^{-1}\right)$, and a broad $2 D$ band $\left(2300-3200 \mathrm{~cm}^{-1}\right)$, consistent with previous reports $[22,30,31]$. It was observed that the intensity ratio of the $D$ and $G$ bands $\left(\mathrm{I}_{\mathrm{D}} / \mathrm{I}_{\mathrm{G}}\right)$ was $\sim 0.65$, which was significantly lower than that previously reported for rGO [22,32]. It is hypothesized that the thermal reduction of TrGO resulted in lower structural disorder and an increase in in-plane crystallinity [33], whereby the disordered structure and defects therein were removed. Furthermore, the XRD spectrum of TrGO exhibited a diffraction peak at $\sim 26.2^{\circ}$, which corresponds to the presence of (002) graphitic planes [34]. Using Bragg's equation, the interplanar spacing $(d)$ was estimated as $\sim 0.334 \mathrm{~nm}$, suggesting the efficient graphitization of the material. This result was clearly supported by HR-TEM, as illustrated in Figure 2c,d. As shown in Figure 2c, the TrGO nanosheets exhibited a smooth layered structure with a lateral dimension of $\sim 2 \mu \mathrm{m}$. The average lattice spacing was estimated as $\sim 0.34 \mathrm{~nm}$ (Figure $2 \mathrm{~d}$, inset), which is in close agreement with the interplanar spacing of the graphite lattice [33].

(a)

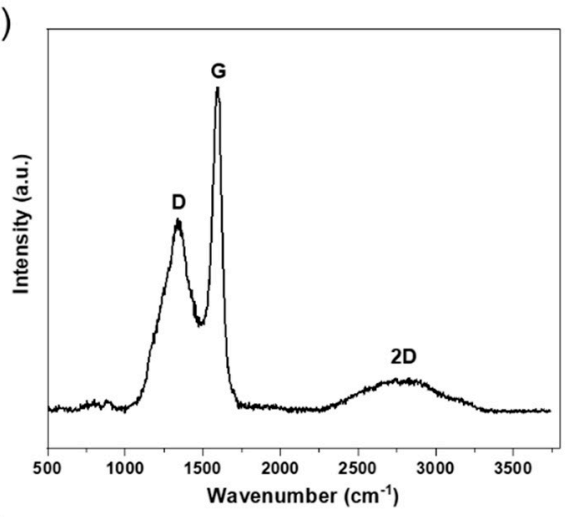

(c)

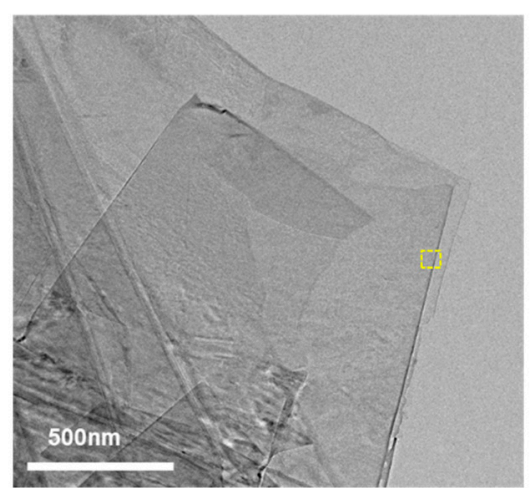

(b)

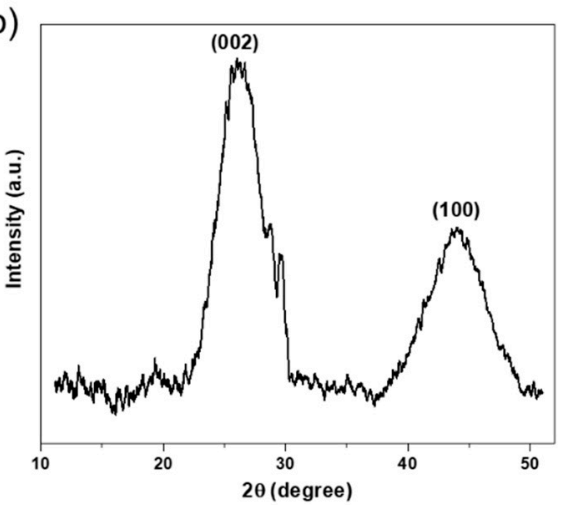

(d)

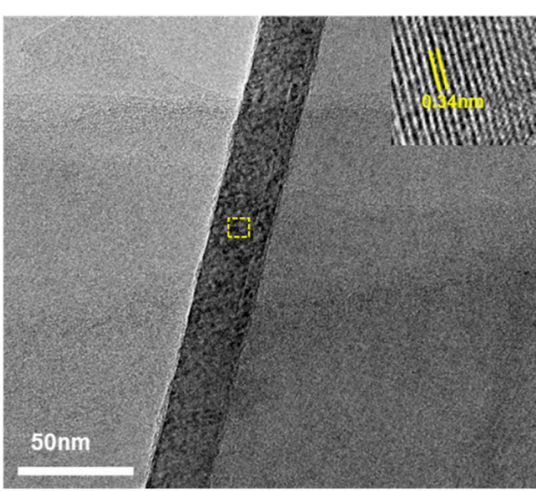

Figure 2. Structural characterization of TrGO synthesized from shellac using (a) Raman spectra and (b) $x$-ray diffraction spectra, (c) high-resolution TEM image $(20,000 \times)$ of few-layered TrGO nanosheets, (d) magnified $(150,000 \times)$ HR-TEM image to validate the crystallinity of TrGO.

The high-resolution $\mathrm{C}-1 \mathrm{~s}$ spectrum of $\operatorname{TrGO}$ was deconvoluted to investigate the presence of different oxygen-containing functional groups, and the results are shown in Figure 3a. The spectrum was deconvoluted into three main peaks, corresponding to $\mathrm{C}=\mathrm{C}$ ( $\mathrm{sp}^{2}$, 
284.4 eV), $\mathrm{C}-\mathrm{OH}$ (hydroxyl, $285.3 \mathrm{eV}$ ), and $\mathrm{C}=\mathrm{O}$ (carbonyl, $287.9 \mathrm{eV}$ ) [35]. These oxygencontaining functional groups play a critical role in the homogeneous dispersion of $\mathrm{TrGO}$ in the PVA matrix, which affects the mechanical strength of PVA-TrGO nanocomposites and will be discussed later. As shown in Figure $3 b-d$, the elemental mapping of $\operatorname{TrGO}(\mathrm{C}$ (red) and $\mathrm{O}$ (green)) revealed the presence of carbon and oxygen in shellac-derived $\operatorname{TrGO}$.

(a)

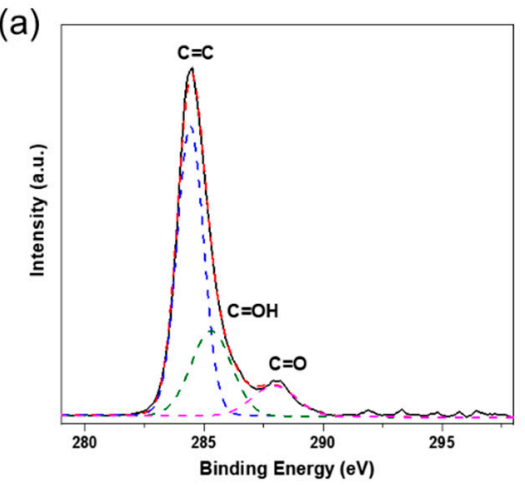

(c)

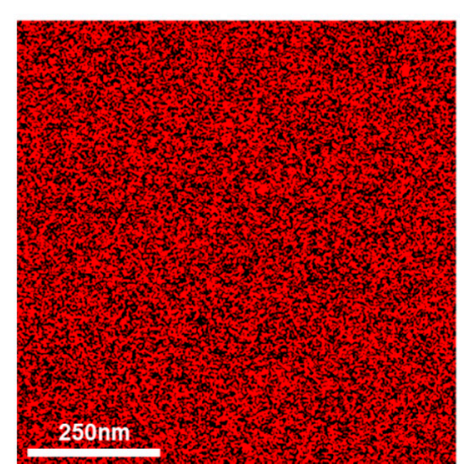

(b)

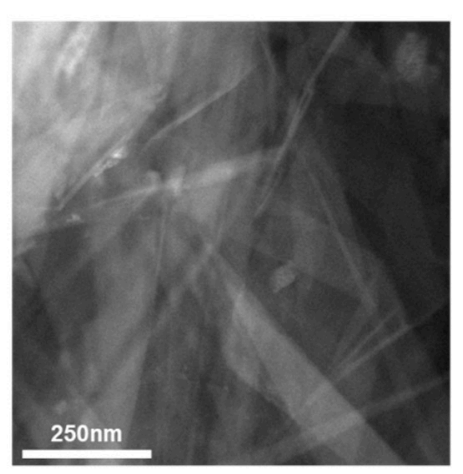

(d)

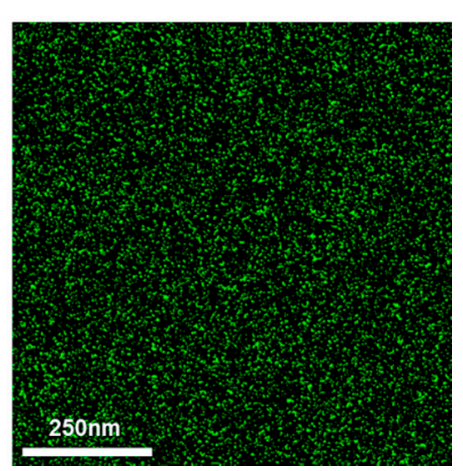

Figure 3. (a) High-resolution carbon (1s) core level XPS spectra, (b) HAADF-STEM image and elemental mapping exhibiting the distribution of (c) carbon (red) atoms and (d) oxygen (green) atoms of shellac-derived TrGO.

\subsection{PVA-TRGO Nanocomposites' Properties \\ 3.2.1. Structural Analysis}

The chemical structure analysis of the PVA-TrGO nanocomposites was performed using Fourier transform infrared (FTIR) spectra, and the results are presented in Figure 4a. The appearance of a broad band $\left(3000-3500 \mathrm{~cm}^{-1}\right)$ in the pure PVA matrix was attributed to the symmetrical stretching vibration of the hydroxyl group, which indicates strong intermolecular and intramolecular hydrogen bonding [36]. Other absorption peaks were assigned as follows: the peaks at $2940 \mathrm{~cm}^{-1}$ and $2910 \mathrm{~cm}^{-1}$ arose from asymmetric $\mathrm{CH}_{2}$ stretching [23,37], while those at $1730,1326,1256$, and $1090 \mathrm{~cm}^{-1}$ were ascribed to $\mathrm{C}=\mathrm{O}$ stretching, $\mathrm{O}-\mathrm{H}$ bending, $\mathrm{C}-\mathrm{H}$ bending, and $\mathrm{C}-\mathrm{O}$ stretching vibrations, respectively, of $\mathrm{PVA}$ (Table 1). However, for the PVA-TrGO nanocomposites, the hydroxyl peaks systematically decreased (from $3370 \mathrm{~cm}^{-1}$ to $3312 \mathrm{~cm}^{-1}$ ) with increasing TrGO concentration, indicating the formation of hydrogen bonds between the hydroxyl groups of PVA and the oxygencontaining functional groups of TrGO. Furthermore, the peak intensity increased with increasing $\operatorname{TrGO}$ concentration up to $1.5 \mathrm{wt} . \%$. The reduction in the peak intensity observed for the PVA-TrGO-2 wt.\% sample can be attributed to the decrease in hydrogen bonds, which was caused by the agglomeration of TrGO sheets by strong van der Waals forces. 
(a)

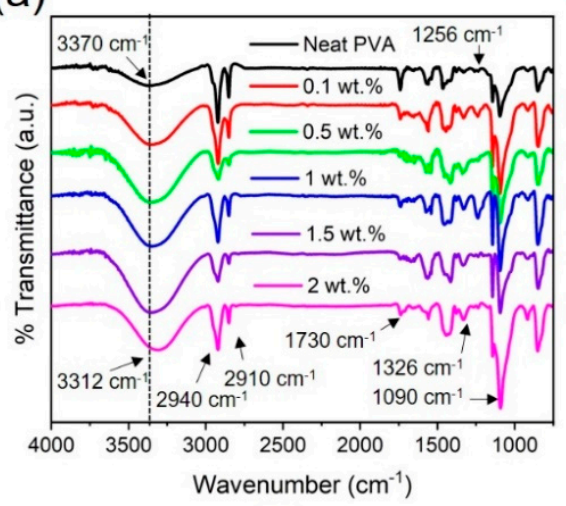

(b)

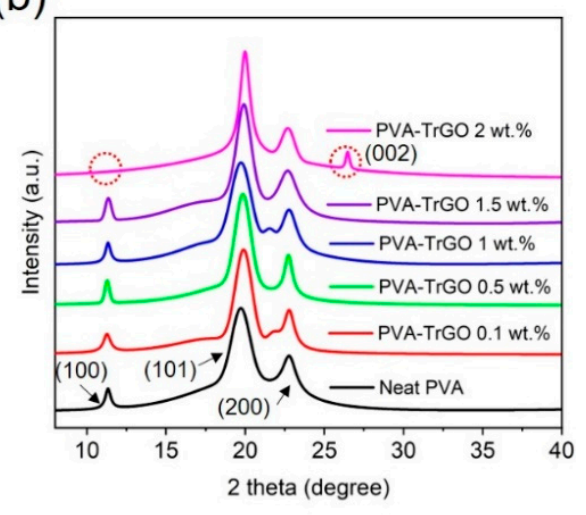

(c)

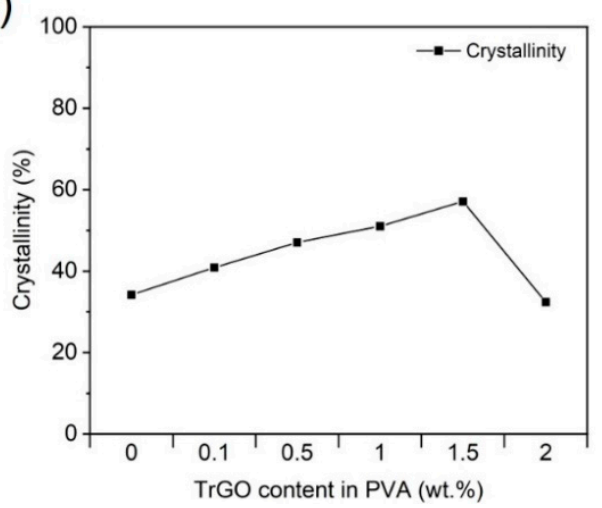

Figure 4. (a) FTIR spectra and (b) WAXD pattern for PVA-TrGO nanocomposites with different TrGO concentrations; black line: pure PVA matrix, red line: PVA-TrGO-0.1 wt. $\%$, green line: PVA-TrGO-0.5 wt.\%, blue line: PVA-TrGO-1 wt.\%, purple line: PVA-TrGO-1.5 wt. \%, pink line: PVA-TrGO-2 wt. $\%$, (c) crystallinity of PVA-TrGO nanocomposites with different TrGO concentrations obtained from WAXD spectra.

Table 1. Band assignments of PVA-TrGO nanocomposites obtained from the FTIR spectra.

\begin{tabular}{cc}
\hline Band $\left.\mathbf{( c m}^{-\mathbf{1}}\right)$ & Assignments \\
\hline 1090 & C-O Stretching, Epoxide Groups of PVA \\
1256 & C-H Bending \\
1326 & $\mathrm{O}-\mathrm{H}$ Bending Vibration \\
1730 & $\mathrm{C}=\mathrm{O}$ Stretching \\
2910,2940 & Asymmetric $\mathrm{CH}_{2}$ Stretching \\
$3000-3050$ & O-H Stretching \\
\hline
\end{tabular}

Figure $4 \mathrm{~b}$ shows the WAXD patterns of the PVA-TrGO nanocomposites with different TrGO concentrations. For the pure PVA matrix, the WAXD patterns exhibited three major peaks at $19.7^{\circ}, 22.6^{\circ}$, and $11.3^{\circ}$, which represent the (101), (200), and (100) planes, respectively [38-40]. As TrGO was introduced in PVA, the WAXD patterns showed diffraction peaks similar to those of pure PVA, which implies that the TrGO sheets were homogeneously dispersed in the PVA matrix. Interestingly, the WAXD diffraction pattern for the PVA-TrGO-2 wt.\% sample exhibited the appearance and disappearance of the characteristic peak of TrGO (002) and pure PVA (100), respectively, as shown by the red dotted circle in Figure $4 \mathrm{~b}$. The development of TrGO peaks at such high concentrations can be attributed to the agglomeration of TrGO nanosheets in the PVA matrix because of the strong van der Waals interactions between the sheets. Still, the crystallinity of PVA was attributed to hydrogen bonding with its branching chains [41]. The stacking of polymer chains increases the WAXD peak intensity and has a strong influence on the crystallinity and physicochemical properties of polymer nanocomposites [36]. As shown in Figure 4c, 
the crystallinity of PVA-TrGO nanocomposites increased up to TrGO concentrations of $1.5 \mathrm{wt} . \%$, which was due to increased intermolecular interactions between the filler and the matrix and resulted in enhanced mechanical properties. This phenomenon will be discussed later.

\subsubsection{Thermal Properties}

DSC analysis was conducted to investigate the effect of $\operatorname{TrGO}$ concentration on the thermal properties of the PVA-TrGO nanocomposites. The melting temperature $\left(T_{m}\right)$, crystallization temperature $\left(T_{c}\right)$, and degree of crystallinity $\left(\% X_{c}\right)$ were calculated from the exothermic heat flow curve, as shown in Figure 5. As listed in Table 2, the $T_{m}$ and $\% X_{c}$ values of the PVA-TrGO nanocomposites increased with increasing $\operatorname{TrGO}$ concentration up to $1.5 \mathrm{wt} . \%$, which was due to the cumulative effect of heat-shielding capability and strong intermolecular interactions between the TrGO fillers and the polymer matrix [42-45]. Furthermore, the high surface-to-volume ratio and high surface energy of $\operatorname{TrGO}$ can also increase the crystallization and chain mobility of PVA [36]. It is worth mentioning that the discrepancy in the crystallinity fraction obtained from DSC and WAXD results has also been shown in previous reports [46-48]. Especially for PVA-TrGO-2wt.\% nanocomposites, the deviation was quite significant, which can be attributed to the following factors: firstly, DSC provides information from the whole sample, whereas WAXD retrieves information within a few $\mu \mathrm{m}$, hence is surface-sensitive. Thus, the inhomogeneous distribution of $\operatorname{TrGO}$ nanofillers in the PVA matrix can lead to a different crystallinity fraction, but with a similar trend [49], as observed here. Secondly, when the material undergoes thermal treatment during DSC measurement, the temperature elevation promotes relaxation, which can cause a partial structural recovery, leading to a deviation from the true crystallinity of the material, as observed using WAXD. Furthermore, the DSC technique affects the nonequilibrium state because of the inherent heating process, whereas the WAXD technique does not include any strong interaction with the measured system, and the sample is not subjected to any strong perturbation [48].

Table 2. DSC data and crystallinities of PVA-TrGO films with different TrGO concentrations.

\begin{tabular}{cccccc}
\hline $\begin{array}{c}\text { TrGO Con- } \\
\text { centration } \\
\text { (wt.\%) }\end{array}$ & $\mathbf{T}_{\mathbf{c}}\left({ }^{\circ} \mathbf{C}\right)$ & $\mathbf{T}_{\mathbf{m}}\left({ }^{\circ} \mathbf{C}\right)$ & $\mathbf{\Delta H}_{\mathbf{m}}{ }^{\mathbf{a}}$ & $\mathbf{X}_{\mathbf{c}}(\mathbf{\%}){ }^{\mathbf{b}}$ & $\mathbf{C I}(\mathbf{\%}){ }^{\mathbf{c}}$ \\
\hline 0 & 183.43 & 212.23 & 29.44 & 21.23 & 34.2 \\
0.1 & 187.65 & 216.77 & 40.5 & 29.2 & 40.89 \\
0.5 & 191.36 & 219.78 & 43.15 & 31.11 & 47.04 \\
1 & 193.56 & 219.95 & 43.39 & 31.28 & 51.04 \\
1.5 & 195.14 & 221.91 & 45.51 & 32.81 & 57.1 \\
2 & 192.06 & 219.23 & 45.03 & 32.47 & 32.42 \\
\hline
\end{tabular}

a Enthalpies of the PVA-TrGO nanocomposites from DSC analysis software. ${ }^{\mathbf{b}}$ Calculated using Equation (2).

c Calculated using Equation (1).

The thermal stability of PVA-TrGO nanocomposites was also measured using TGA, and the weight loss curves are shown in Figure 6a. As displayed in Table 3, up to a TrGO concentration of $1.5 \mathrm{wt} . \%$, the degradation temperature at the weight loss of $5 \%$ increased gradually (Figure 6b) from $135^{\circ} \mathrm{C}$ to $219^{\circ} \mathrm{C}$. This indicated that the high heat resistance of TrGO contributes significantly to the thermal stability of PVA films [50]. However, for the TrGO- $2 \mathrm{wt} . \%$ sample, it decreased to $215^{\circ} \mathrm{C}$, which could be due to the high amount of TrGO in the PVA matrix causing agglomeration of the TrGO sheets, and thus, a decrease in heat resistance. The TrGO residue after thermal decomposition was found to increase gradually with increasing TrGO concentration. 
(a)

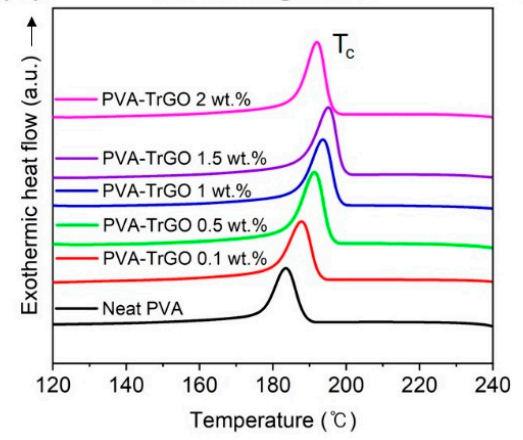

(c) (b)

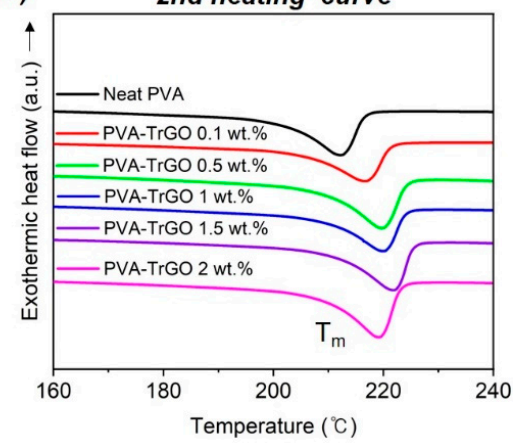

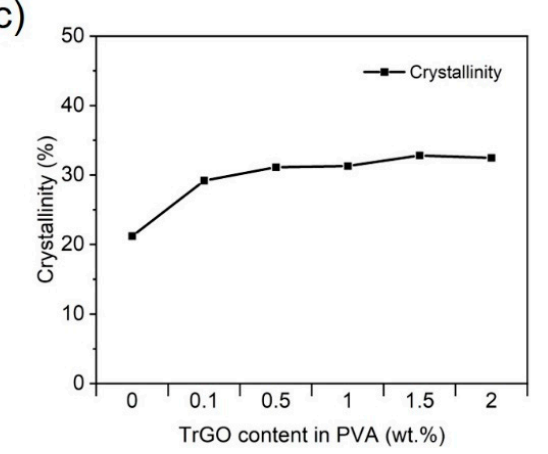

Figure 5. Non-isothermal DSC scans of (a) first cooling curves and (b) second heating curves of PVA-TrGO nanocomposites; (c) calculated crystallinity of the PVA-TrGO nanocomposites from DSC scans.

(a)

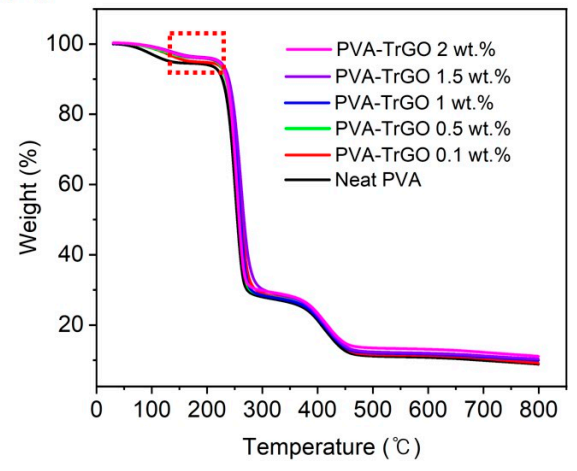

(b)

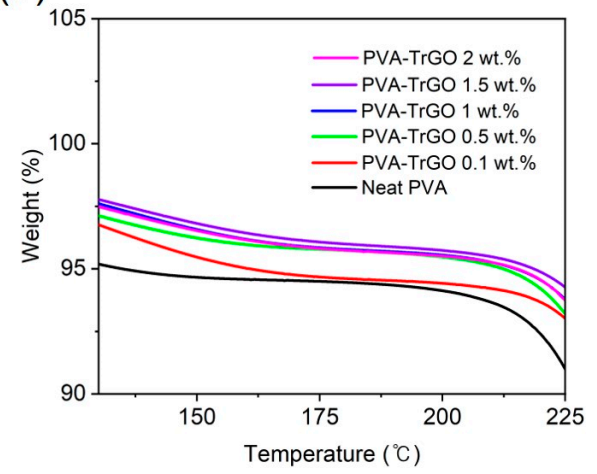

Figure 6. TGA thermographs of (a) PVA-TrGO nanocomposites with different TrGO concentration, (b) high-magnification region $\left(130^{\circ} \mathrm{C}-225^{\circ} \mathrm{C}\right)$ displaying the $5 \%$ weight loss.

Table 3. Values of $5 \mathrm{wt}$.\% loss temperature and percentage residue of PVA films at different TrGO concentrations.

\begin{tabular}{|c|c|c|}
\hline $\begin{array}{l}\text { TrGO Concentration } \\
\text { (wt. \%) }\end{array}$ & $\begin{array}{c}5 \% \text { Weight Loss Temperature, } T_{D}{ }^{5 \%} \\
\left({ }^{\circ} \mathrm{C}\right)\end{array}$ & $\begin{array}{l}\text { Residual Amount at } \\
\qquad 800{ }^{\circ} \mathrm{C}(\%)\end{array}$ \\
\hline 0 & 134.75 & 6.78 \\
\hline 0.1 & 160.89 & 7.51 \\
\hline 0.5 & 212.31 & 7.61 \\
\hline 1 & 214.86 & 7.69 \\
\hline 1.5 & 218.54 & 7.83 \\
\hline 2 & 215.09 & 8.83 \\
\hline
\end{tabular}




\subsubsection{Morphology}

The reported FE-SEM images (Figure 7) show the cross-sectional morphology of the fractured PVA-TrGO nanocomposites. For the pure PVA matrix, the surface appeared to be highly porous, as shown in Figure 7a. However, for PVA-TrGO-1 wt.\% (Figure 7b), the surface exhibited a layered structure aligned in one particular direction and a notable roughness, as observed earlier [51]. Interestingly, for the PVA-TrGO-1.5 wt.\% sample, the surface appeared to be smoother than that of the PVA-TrGO- 1 wt.\% sample. This might be due to the stable dispersion of TrGO without significant aggregation, leading to a smooth surface morphology. A homogeneous dispersion also improves the chemical affinity between $\operatorname{TrGO}$ and PVA, which increases the interfacial interaction, resulting in enhanced mechanical strength. However, when the TrGO concentration was increased to $2 \mathrm{wt} . \%$, as shown in Figures $7 \mathrm{~d}$ and S2, local aggregation of the TrGO nanosheets in the PVA matrix could be observed because of the development of strong van der Waals attractive forces between the sheets due to the high TrGO concentration.

(a)

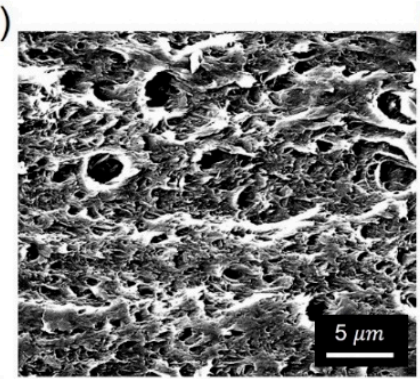

(c)

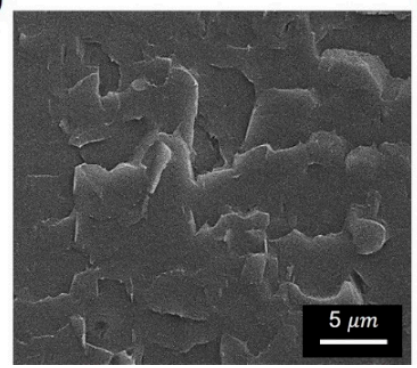

(b)

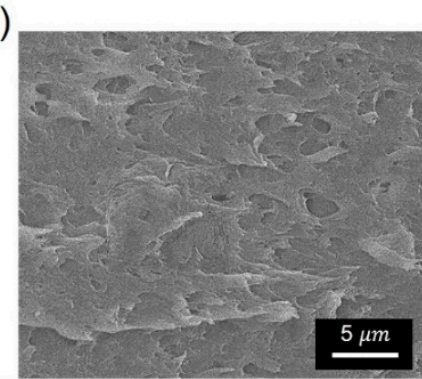

(d)

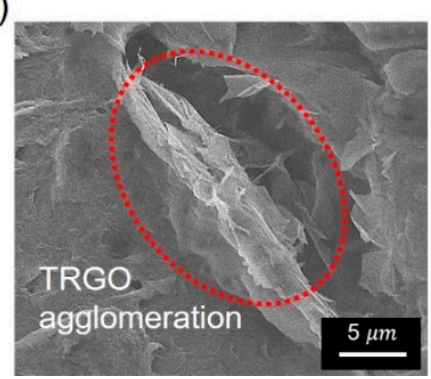

Figure 7. Cross-sectional SEM images $(10000 \times)$ of fractured (a) pure PVA matrix and PVA-TrGO nanocomposites with $\operatorname{TrGO}$ concentrations of (b) 1 wt.\%, (c) $1.5 \mathrm{wt} . \%$, and (d) $2 \mathrm{wt} . \%$.

\subsubsection{Mechanical Properties}

The tensile properties of the different PVA-TrGO nanocomposite samples were analyzed using a film tension test. As shown in Figure 8, the tensile strength and modulus of the PVA-TrGO-1.5 wt.\% sample were $~ 51.5 \mathrm{MPa}$ and $\sim 750 \mathrm{MPa}$, respectively, which corresponds to $\sim 98.7 \%$ and $97.4 \%$ increases, respectively, compared to those of the pure PVA matrix ( $25.9 \mathrm{MPa}$ and $380 \mathrm{MPa}$, respectively). The elongation at break decreased with an increasing $\operatorname{TrGO}$ concentration. It should be noted that the $\operatorname{TrGO}$ sheets are strong and rigid units, and the distribution of these units within the PVA matrix enhanced certain mechanical properties, such as stiffness and rigidity. This is because intermolecular interactions, such as hydrogen bonding between oxygen functional groups in $\operatorname{TrGO}$ and $-\mathrm{OH}$ groups in PVA, were induced, as shown in Figure 9. However, at the high concentration of $2 \mathrm{wt} . \% \mathrm{TrGO}$, the tensile properties deteriorated significantly because of TrGO agglomeration caused by van der Waal forces. As shown in Figure 10, the increase in the tensile properties of the presently investigated PVA-TrGO nanocomposites was compared with previously published results. Aslam et al. reported that addition of $0.02 \mathrm{wt} . \%$ of rGO to a PVA matrix enhanced the tensile strength and modulus by $71.4 \%$ and $12.5 \%$, respectively, when compared to the control sample [52]. Mo et al. reported that addition of $10 \mathrm{wt} . \%$ of rGO in a PVA matrix enhanced the tensile strength and modulus by $66.4 \%$ and $21.7 \%$, 
respectively [38]. Li et al. prepared PVA-rGO-3 wt.\% nanocomposites by a solvothermal reduction process and reported a 53\% and 52.6\% increase in the tensile strength and modulus, respectively [53]. In addition, Yang et al. reported that the introduction of $3.5 \mathrm{wt} . \%$ graphene into a PVA matrix also improved the tensile strength and modulus by $31.8 \%$ and $15.5 \%$, respectively [51]. However, in this study, tensile strength and modulus of the nanocomposite were improved by $98.7 \%$ and $97.4 \%$, respectively, significantly more than what reported previously.

(a)

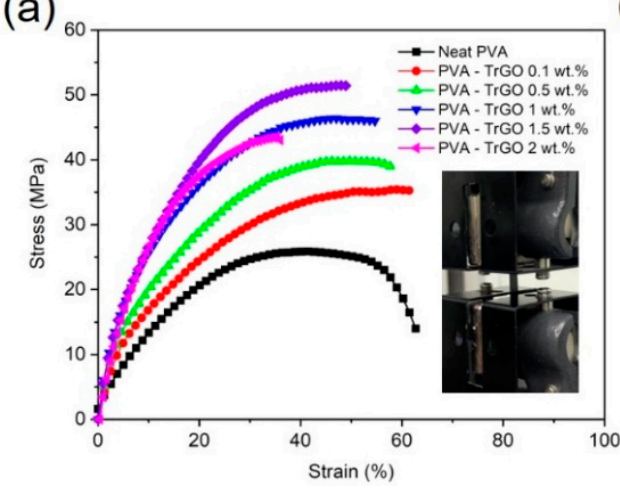

(b)

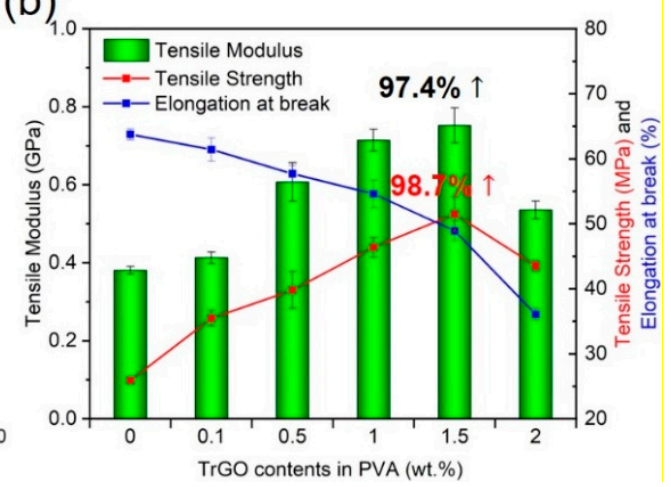

Figure 8. (a) Tensile stress-strain curves and (b) tensile strength, modulus, and elongation at break of PVA-TrGO nanocomposites with different $\operatorname{TrGO}$ concentrations.

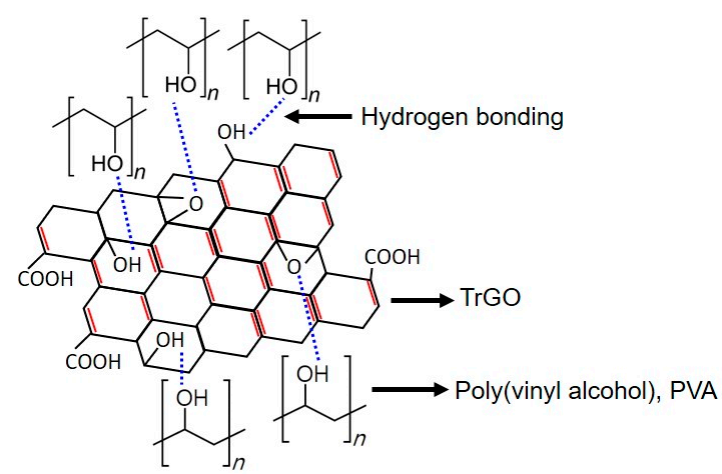

Figure 9. Schematic representation of the intermolecular interaction between the PVA chain and the shellac-derived TrGO.

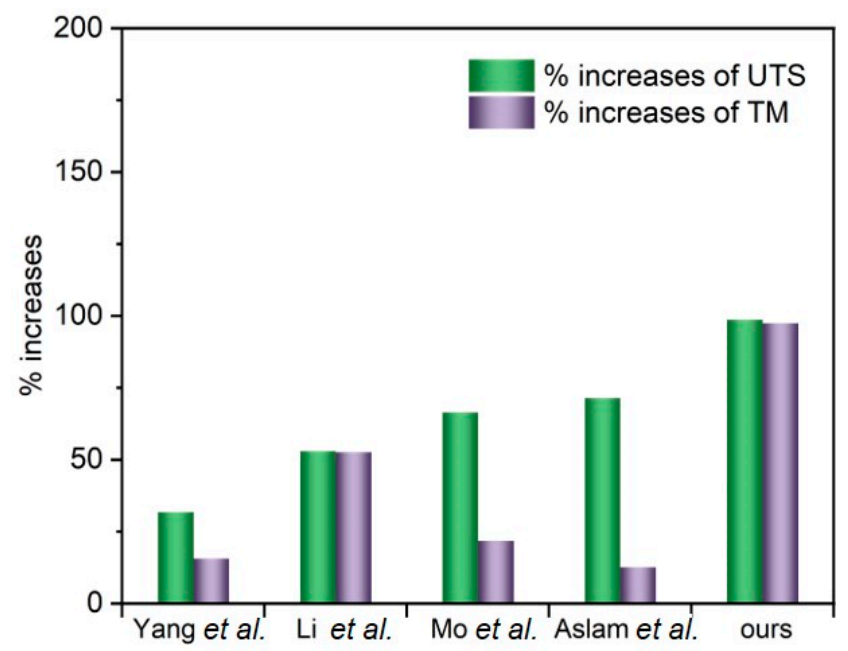

Figure 10. Comparison of percentage increases in the ultimate tensile strength (UTS) and tensile modulus (TM) of PVA-rGO composites with values reported in previous studies. 
The dynamic mechanical properties of the PVA-TrGO nanocomposites were used to investigate the elastic stiffness as a function of temperature. As shown in Figure 11a, the PVA-TrGO nanocomposites exhibited a systematic increase in the storage modulus $\left(E^{\prime}\right)$ with increasing TrGO concentration. In particular for the PVAy-TrGO-1.5 wt.\% sample, $E^{\prime}$ increased to $\sim 5.32 \mathrm{GPa}$, which represents a $69 \%$ improvement compared to that of the pure PVA matrix ( $3.15 \mathrm{GPa}$ ). The glass transition temperature $\left(T_{g}\right)$ was also determined from the peak temperature of the tan $\delta$ curves and is shown in Figure 11b. As expected, for the PVA-TrGO-1.5 wt. \% sample $T_{g}$ increased to $93.6{ }^{\circ} \mathrm{C}$, which represents a $\sim 7.4 \%$ improvement compared to that of the pure PVA matrix $\left(87.2^{\circ} \mathrm{C}\right)$, which was ascribed to the strong attachment of TrGO to the pure PVA matrix, leading to increased rigidity (Figure 8b).

(a)

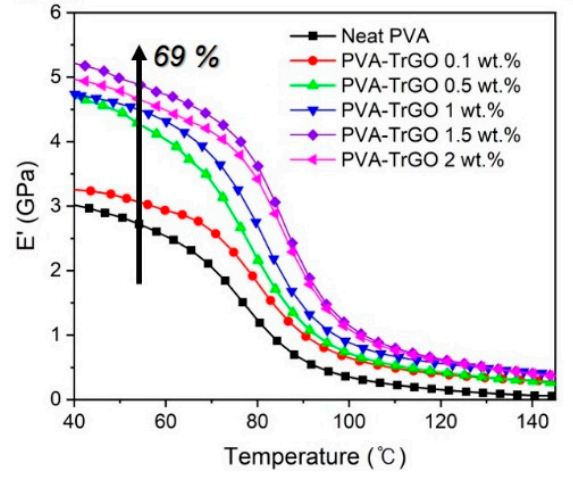

(b)

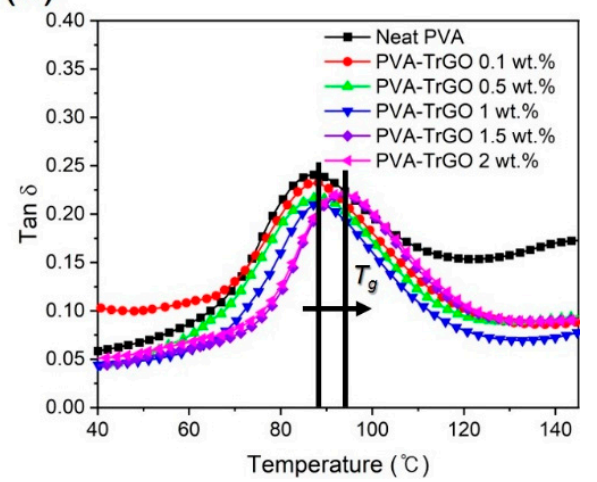

Figure 11. (a) Storage modulus $\left(\mathrm{E}^{\prime}\right)$ and (b) $\tan \delta$ of the PVA-TrGO nanocomposites with different TrGO concentrations.

\subsubsection{Antibacterial Activity}

To investigate the potential of PVA-TrGO nanocomposites for biomedical applications, the antibacterial activity of the PVA-TrGO- $1.5 \mathrm{wt} \%$ sample was studied. This sample was chosen because it exhibited the best thermal and mechanical properties among all samples. Pathogenic bacterial strains of Gram-negative E. coli (ATCC ${ }^{2} 25922^{\mathrm{TM}}$ ) were used to evaluate the antibacterial activity by calculating the CFUs. Figure $12 \mathrm{a}-\mathrm{c}$ shows the viability loss of the bacteria after $3 \mathrm{~h}$ of incubation with pure PVA, pure TrGO, and PVA-TrGO-1.5 wt \%. Quantitative analysis based on CFUs, as illustrated in Figure 12d, indicated significantly reduced bacterial activity in the case of PVA-TrGO nanocomposites, showing an impressive $\sim 3.5 \mathrm{log}$, which represents more than $96 \%$ reduction of $E$. coli viability, while the pure PVA matrix exhibited negligible antibacterial properties. The high antibacterial activity of the nanocomposites can be attributed to either of the following explanations: (a) direct contact of the bacteria with the edges of $\operatorname{TrGO}$, which were able to pierce the cellular membrane, or (b) wrapping of TrGO around the bacteria thanks to its twodimensional structure, which prevented nutrient uptake by the bacteria, resulting in cell death $[54,55]$. The relatively lower antibacterial activity of pure $\operatorname{TrGO}$ flakes with respect to the PVA-TrGO nanocomposite can be attributed to its strong tendency for aggregation due to the presence of strong van der Waals interactions between the nanosheets [56]. This restacking tendency of TrGO nanosheets causes the loss of its two-dimensional properties, leading to lower antibacterial activity with respect to homogeneously dispersed $\mathrm{TrGO}$ in a PVA matrix [57]. These results suggest that the PVA-TrGO nanocomposites, with superior mechanical and antibacterial properties, have the potential to become important materials in several biomedical applications. 
(a)

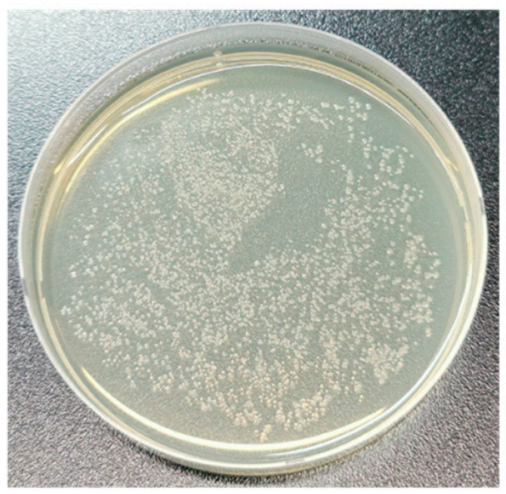

(c)

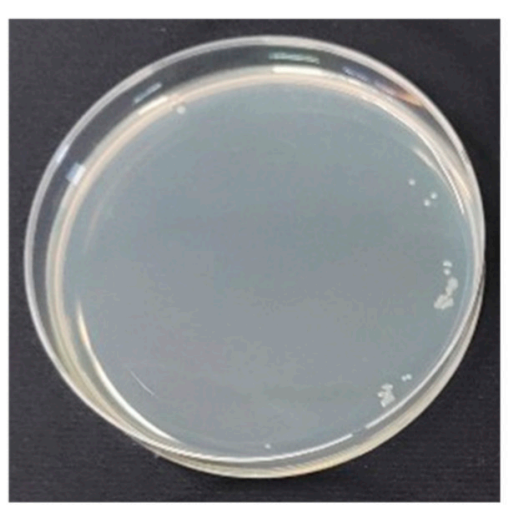

(b)

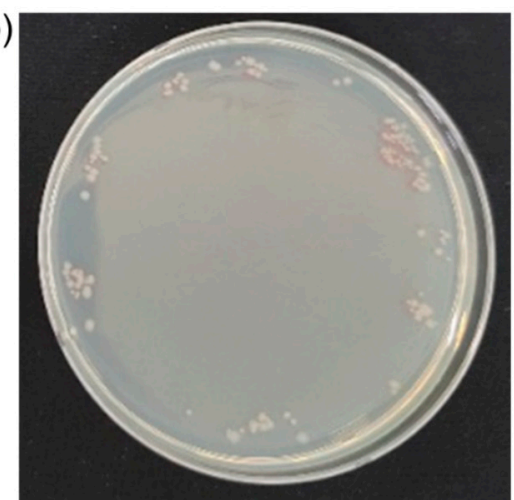

(d)

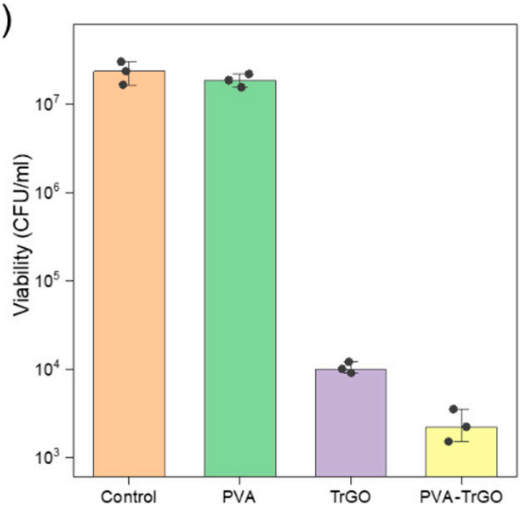

Figure 12. Antibacterial activity expressed as colony-forming units (CFU)/ $\mathrm{ml}$ of (a) the pure PVA polymer matrix, (b) pure TrGO, and (c) PVA-TrGO $1.5 \mathrm{wt} \%$ nanocomposite toward Escherichia coli (ATCC ${ }^{2} 25922^{\mathrm{TM}}$ ) and (d) number of $E$. coli viable bacteria, calculated from CFU. Three independent measurements were performed for statistical analysis.

\section{Conclusions}

In conclusion, shellac-derived TrGO was synthesized by a single-step thermal reduction process and exhibited homogeneous dispersion in a PVA matrix, allowing for simple solution casting to produce PVA-TrGO nanocomposites. The homogeneous dispersion of TrGO throughout the PVA matrix is attributed to the presence of strong hydrogen bonds between the hydroxyl groups of PVA and the oxygen-containing functional groups of shellac-derived TrGO, resulting in enhanced thermal and mechanical properties. In particular, in the samples containing $1.5 \mathrm{wt} \% \mathrm{TrGO}$, the tensile strength, tensile modulus, and storage modulus of the PVA-TrGO nanocomposites were increased by $\sim 98.7 \%, \sim 97.4 \%$, and $\sim 69 \%$, respectively. Furthermore, the nanocomposite also showed superior bactericidal performance, showing more than $96 \%$ antibacterial effectiveness towards E. coli, compared to the pure PVA matrix. These findings suggest that shellac-derived $\operatorname{TrGO}$ can be used as a reinforcement material for the synthesis of polymer nanocomposites for various biomedical applications.

Supplementary Materials: The following are available online at https:/ / www.mdpi.com/2073-436 0/13/4/615/s1. Figure S1: FT-IR spectra of shellac powder, Figure S2. FESEM $(30000 \times)$ showing TrGO ag-glomeration in the PVA-TrGO-2wt.\% nanocomposite (Red circular area in Figure 7d).

Author Contributions: Conceptualization, B.-G.C. and S.R.J.; methodology, B.-G.C., S.L. and S.R.J.; validation, B.-G.C., S.L., S.-K.K., and S.R.J.; formal analysis, B.-G.C., S.R.J. and S.L.; investigation, B.-G.C. and S.R.J.; data curation, B.-G.C., S.R.J., S.L., and S.-K.K.; writing-original draft preparation, B.-G.C. and S.R.J.; writing - review and editing, G.-H.K. and Y.-B.P.; supervision, G.-H.K. and Y.-B.P.; funding acquisition, G.-H.K. and Y.-B.P. All authors have read and agreed to the published version of the manuscript. 
Funding: The research was financially supported by the Institute of Information and Communications Technology Planning and Evaluation (IITP) grant funded by the Korean government (MSIT) (No. 2018-0-00756), the Nano-Material Technology Development Program through the National Research Foundation (NRF) funded by the Ministry of Science and ICT of Korea (Grant No. 2016M3A7B4027697), and the Basic Science Research Program through the National Research Foundation of Korea (NRF) funded by the Ministry of Education (NRF-2016R1D1A1B03931376 NRF-2020R1A4A2002728).

Institutional Review Board Statement: Not applicable.

Informed Consent Statement: Not applicable.

Data Availability Statement: The data presented in this study are available on request from the corresponding author.

Conflicts of Interest: The authors declare that there are no conflicts of interest. The funders had no role in the design of the study; in the collection, analyses, or interpretation of data; in the writing of the manuscript, or in the decision to publish the results.

\section{References}

1. Hwang, S.H.; Kang, D.; Ruoff, R.S.; Shin, H.S.; Park, Y.B. Poly(vinyl alcohol) Reinforced and Toughenedwith Poly(dopamine)Treated Graphene Oxide, and Its Use for Humidity Sensing. ACS Nano 2014, 8, 6739-6747. [CrossRef]

2. Kashyap, S.; Pratihar, S.K.; Behera, S.K. Strong and ductile graphene oxide reinforced PVA nanocomposites. J. Alloys Compd. 2016, 684, 254-260. [CrossRef]

3. Zhou, K.; Gui, Z.; Hu, Y. Facile synthesis of LDH nanoplates as reinforcing agents in PVA nanocomposites. Polym. Adv. Technol. 2017, 28, 386-392. [CrossRef]

4. Yahia, I.S.; Mohammed, M.I. Facile synthesis of graphene oxide/PVA nanocomposites for laser optical limiting: Band gap analysis and dielectric constants. J. Mater. Sci. Mater. Electron. 2018, 29, 8555-8563. [CrossRef]

5. Huang, D.; Wang, A. Non-covalently functionalized multiwalled carbon nanotubes by chitosan and their synergistic reinforcing effects in PVA films. RSC Adv. 2013, 3, 1210-1216. [CrossRef]

6. He, Y.; Wang, X.; Wu, D.; Gong, Q.; Qiu, H.; Liu, Y.; Wu, T.; Ma, J.; Gao, J. Biodegradable amylose films reinforced by graphene oxide and polyvinyl alcohol. Mater. Chem. Phys. 2013, 142, 1-11. [CrossRef]

7. Ha, H.O.; Kim, D.S. Stability Change of Poly(vinyl alcohol)-Iodine Complexes Due to Moisture Absorption. Polym. Korea 2017, 41, 507-513. [CrossRef]

8. Baldino, L.; Aragón, J.; Mendoza, G.; Irusta, S.; Cardea, S.; Reverchon, E. Production, characterization and testing of antibacterial PVA membranes loaded with $\mathrm{HA}-\mathrm{Ag}_{3} \mathrm{PO}_{4}$ nanoparticles, produced by SC-CO phase inversion. J. Chem. Technol. Biotechnol. 2019, 94, 98-108. [CrossRef]

9. Wang, Z.; Zhao, S.; Hong, L.; Huang, J. Preparation and Properties of Silver-Based Cellulose/Polyvinyl Alcohol Antibacterial Materials. J. Inorg. Organomet. Polym. Mater. 2020, 30, 4382-4393. [CrossRef]

10. Borriello, C.; Maria, A.D.; Jovic, N.; Montone, A.; Schwarz, M.; Antisari, M.V. Mechanochemical Exfoliation of Graphite and Its Polyvinyl Alcohol Nanocomposites with Enhanced Barrier Properties. Mater. Manuf. Process. 2009, 24, 1053-1057. [CrossRef]

11. Chuang, W.Y.; Young, T.H.; Chiu, W.Y.; Lin, C.Y. The effect of polymer additives on the structure and permeability of poly(vinyl alcohol) asymmetric membranes. Polymer 2000, 41, 5633-5641. [CrossRef]

12. Bernard, J.; Favier, A.; Davis, T.P.; Kowollik, C.B.; Stenzel, M.H. Synthesis of poly(vinyl alcohol) combs via MADIX/RAFT polymerization. Polymer 2006, 47, 1073-1080. [CrossRef]

13. Patro, T.U.; Wagner, H.D. Layer-by-layer assembled PVA/Laponite multilayer free-standing films and their mechanical and thermal properties. Nanotechnology 2011, 22, 455706. [CrossRef]

14. Zhang, T.L.X.; Sreekumar, T.V.; Kumar, S.; Moore, V.C.; Hauge, R.H.; Smalley, R.E. Poly(vinyl alcohol)/SWNT Composite Film. Nano Lett. 2003, 3, 1285-1288. [CrossRef]

15. Chen, X. Preparation and property of $\mathrm{TiO}_{2}$ nanoparticle dispersed polyvinyl alcohol composite materials. J. Mater. Sci. Lett. 2002, 21, 1637-1639. [CrossRef]

16. Stankovich, S.; Dikin, D.A.; Dommett, G.H.; Kohlhaas, K.M.; Zimney, E.J.; Stach, E.A.; Piner, R.D.; Nguyen, S.T.; Ruoff, R.S. Graphene-based composite materials. Nature 2006, 442, 282-286. [CrossRef] [PubMed]

17. Li, W.C.X.; An, J.; Kim, S.; Nah, J.; Yang, D.; Piner, R.; Velamakanni, A.; Jung, I.; Tutuc, E.; Banerjee, S.K.; et al. Large-Area Synthesis of High-Quality and Uniform Graphene Films on Copper Foils. Science 2009, 324, 4. [CrossRef]

18. Ji, X.; Xu, Y.; Zhang, W.; Cui, L.; Liu, J. Review of functionalization, structure and properties of graphene/polymer composite fibers. Compos. Part A Appl. Sci. Manuf. 2016, 87, 29-45. [CrossRef]

19. Han, N.R.; Cho, J.W. Click coupled stitched graphene sheets and their polymer nanocomposites with enhanced photothermal and mechanical properties. Compos. Part A Appl. Sci. Manuf. 2016, 87, 78-85. [CrossRef]

20. Huang, Y.; Qin, Y.; Zhou, Y.; Niu, H.; Yu, Z.Z.; Dong, J.Y. Polypropylene/Graphene Oxide Nanocomposites Prepared by In Situ Ziegler-Natta Polymerization. Chem. Mater. 2010, 22, 4096-4102. [CrossRef] 
21. Tripathi, S.N.; Rao, G.S.S.; Mathur, A.B.; Jasra, R. Polyolefin/graphene nanocomposites: A review. RSC Adv. 2017, 7, 23615-23632. [CrossRef]

22. Shao, L.; Li, J.; Zhang, Y.; Gong, S.; Zhang, H.; Wang, Y. The effect of the reduction extent on the performance of graphene/poly(vinyl alcohol) composites. J. Mater. Chem. A 2014, 34, 14173-14180. [CrossRef]

23. Bao, C.; Guo, Y.; Song, L.; Hu, Y. Poly(vinyl alcohol) nanocomposites based on graphene and graphite oxide: A comparative investigation of property and mechanism. J. Mater. Chem. 2011, 21, 13942-13950. [CrossRef]

24. Vladu, M.I.; Głowacki, E.D.; Schwabegger, G.; Leonat, L.; Akpinar, H.Z.; Sitter, H.; Bauer, S.; Sariciftci, N.S. Natural resin shellac as a substrate and a dielectric layer for organic field-effect transistors. Green Chem. 2013, 15, 1473-1476. [CrossRef]

25. Baek, S.W.; Ha, J.W.; Yoon, M.; Hwang, D.H.; Lee, J. Shellac Films as a Natural Dielectric Layer for Enhanced Electron Transport in Polymer Field-Effect Transistors. ACS Appl. Mater. Interfaces 2018, 10, 18948-18955. [CrossRef]

26. Byun, S.J.; Lim, H.; Shin, G.Y.; Han, T.H.; Oh, S.H.; Ahn, J.H.; Choi, H.C.; Lee, T.W. Graphenes Converted from Polymers. J. Phys. Chem. Lett. 2011, 2, 493-497. [CrossRef]

27. Joshi, S.R.; Sharma, A.; Kim, G.H.; Jang, J. Low cost synthesis of reduced graphene oxide using biopolymer for influenza virus sensor. Mater. Sci. Eng. C Mater. Biol. Appl. 2020, 108, 110465. [CrossRef]

28. Joshi, S.R.; Kim, B.; Kim, S.K.; Song, W.; Park, K.; Kim, G.H.; Shin, H. Low-Cost and Fast-Response Resistive Humidity Sensor Comprising Biopolymer-Derived Carbon Thin Film and Carbon Microelectrodes. J. Electrochem. Soc. 2020, 167, 147511. [CrossRef]

29. Chanda, A.; Rajkonwar, N.; Masood, K.B.; Singh, J.; Shukla, P. Study of bio-polymer derived graphene oxide-ZnO nano-composite thin films. In Proceedings of the 3rd International Conference on Condensed Matter and Applied Physics (ICC-2019), Rajasthan, India, 14-15 October 2019.

30. Cho, B.G.; Joshi, S.R.; Lee, J.; Park, Y.B.; Kim, G.H. Direct growth of thermally reduced graphene oxide on carbon fiber for enhanced mechanical strength. Compos. Part B Eng. 2020, 193. [CrossRef]

31. Singhbabu, Y.N.; Choudhary, S.K.; Shukla, N.; Das, S.; Sahu, R.K. Observation of large positive magneto-resistance in bubble decorated graphene oxide films derived from shellac biopolymer: A new carbon source and facile method for morphologycontrolled properties. Nanoscale 2015, 7, 6510-6519. [CrossRef]

32. Singhbabu, Y.N.; Sivakumar, B.; Choudhary, S.K.; Das, S.; Sahu, R.K. Corrosion-protective reduced graphene oxide coated cold rolled steel prepared using industrial setup: A study of protocol feasibility for commercial production. Surf. Coat. Technol. 2018, 349, 119-132. [CrossRef]

33. Feng, H.; Cheng, R.; Zhao, X.; Duan, X.; Li, J. A loJw-temperature method to produce highly reduced graphene oxide. Nat. Commun. 2013, 4, 1539. [CrossRef]

34. Wu, X.; Li, H.; Cheng, K.; Qiu, H.; Yang, J. Modified graphene/polyimide composite films with strongly enhanced thermal conductivity. Nanoscale 2019, 11, 8219-8225. [CrossRef] [PubMed]

35. Stobinski, L.; Lesiak, B.; Malolepszy, A.; Mazurkiewicz, M.; Mierzwa, B.; Zemek, J.; Jiricek, P.; Bieloshapka, I. Graphene oxide and reduced graphene oxide studied by the XRD, TEM and electron spectroscopy methods. J. Electron. Spectrosc. 2014, 195, 145-154. [CrossRef]

36. Aslam, M.; Kalyar, M.A.; Raza, Z.A. Polyvinyl alcohol: A review of research status and use of polyvinyl alcohol based nanocomposites. Polym. Eng. Sci. 2018, 58, 2119-2132. [CrossRef]

37. Wang, T.; Li, Y.; Geng, S.; Zhou, C.; Jia, X.; Yang, F.; Zhang, L.; Ren, X.; Yang, H. Preparation of flexible reduced graphene oxide/poly(vinyl alcohol) film with superior microwave absorption properties. RSC Adv. 2015, 5, 88958-88964. [CrossRef]

38. Mo, S.; Peng, L.; Yuan, C.; Zhaom, C.; Tang, W.; Ma, C.; Shen, J.; Yang, W.; Yu, Y.; Min, Y.; et al. Enhanced properties of poly(vinyl alcohol) composite films with functionalized graphene. RSC Adv. 2015, 5, 97738-97745. [CrossRef]

39. Liu, K.W.Y.; Luo, F.; Lu, M.; Xiao, F.; Du, X.; Zhang, S.; Liang, L.; Lu, M. Significantly enhanced thermal conductivity in polyvinyl alcohol composites enabled by dopamine modified graphene nanoplatelets. Compos. Part A Appl. Sci. Manuf. 2019, 117, 134-143. [CrossRef]

40. Li, J.; Shao, L.; Zhou, X.; Wang, Y. Fabrication of high strength PVA/rGO composite fibers by gel spinning. RSC Adv. 2014, 4, 43612-43618. [CrossRef]

41. Hong, P.D.; Chen, J.H.; Wu, H.L. Solvent effect on structural change of poly(vinyl alcohol) physical gels. J. Appl. Polym. Sci. 1998, 69, 2477-2486. [CrossRef]

42. Kim, S.W.; Choi, H.M. Enhancement of thermal, mechanical, and barrier properties of ethylene vinyl alcohol copolymer by incorporation of graphene nanosheets. High Perform. Polym. 2014, 27, 694-704. [CrossRef]

43. Zhu, Y.; Wang, H.; Zhu, J.; Chang, L.; Ye, L. Nanoindentation and thermal study of polyvinylalcohol/graphene oxide nanocomposite film through organic/inorganic assembly. Appl. Surf. Sci. 2015, 349, 27-34. [CrossRef]

44. Albert, E.L.; Abdullah, C.A.C.; Shiroshaki, Y. Synthesis and characterization of graphene oxide functionalized with magnetic nanoparticle via simple emulsion method. Results Phys. 2018, 11, 944-950. [CrossRef]

45. Huang, G.; Gao, J.; Wang, X.; Liang, H.; Ge, C. How can graphene reduce the flammability of polymer nanocomposites? Mater. Lett. 2012, 66, 187-189. [CrossRef]

46. Samios, D.; Lima, M.F.S. Thermodynamic behavior of deformed semicrystalline polymers at temperatures between $\mathrm{T}_{\mathrm{g}}$ and $\mathrm{T}_{\mathrm{m}} . J$. Polym. Eng. 1997, 17, 14. [CrossRef]

47. Garcia, I.T.S.; Samios, D. Thermomechanical behaviour of semicrystalline polymers submitted to plane-strain compression. Polymer 1998, 39, 7. [CrossRef] 
48. Lima, M.F.S.; Vasconcellos, M.A.Z.; Samios, D. Crystallinity changes in plastically deformed isotactic polypropylene evaluated by $\mathrm{x}$-ray diffraction and differential scanning calorimetry methods. J. Polym. Sci. Part B Polym. Phys. 2002, 40, 896-903. [CrossRef]

49. Yazdani, A.; Hohne, G.W.H.; Misture, S.T.; Graeve, O.A. A method to quantify crystallinity in amorphous metal alloys: A differential scanning calorimetry study. PLOS ONE 2020, 15, e0234774. [CrossRef] [PubMed]

50. Park, G.T.; Chang, J.H. Comparison of Properties of PVA Nanocomposites Containing Reduced Graphene Oxide and Functionalized Graphene. Polymers 2019, 11, 450. [CrossRef] [PubMed]

51. Yang, X.; Li, L.; Shang, S.; Tao, X.M. Synthesis and characterization of layer-aligned poly(vinyl alcohol)/graphene nanocomposites. Polymer 2010, 51, 3431-3435. [CrossRef]

52. Aslam, M.; Kalyar, M.A.; Raza, Z.A. Fabrication of reduced graphene oxide nanosheets doped PVA composite films for tailoring their opto-mechanical properties. Appl. Phys. A 2017, 123. [CrossRef]

53. Li, J.; Shao, L.; Yuan, L.; Wang, Y. A novel strategy for making poly(vinyl alcohol)/reduced graphite oxide nanocomposites by solvothermal reduction. Mater. Des. (1980-2015) 2014, 54, 520-525. [CrossRef]

54. Zou, X.; Zhang, L.; Wang, Z.; Luo, Y. Mechanisms of the Antimicrobial Activities of Graphene Materials. J. Am. Chem. Soc. 2016, 138, 2064-2077. [CrossRef] [PubMed]

55. Carpio, I.E.M.; Santos, C.M.; Wei, X.; Rodrigues, D.F. Toxicity of a polymer-graphene oxide composite against bacterial planktonic cells, biofilms, and mammalian cells. Nanoscale 2012, 4, 4746-4756. [CrossRef] [PubMed]

56. Moghayedi, M.; Goharshadi, E.K.; Ghazvini, K.; Ahmadzadeh, H.; Ranjbaran, L.; Masoudi, R.; Ludwig, R. Kinetics and mechanism of antibacterial activity and cytotoxicity of Ag-RGO nanocomposite. Colloids Surf. B. 2017, 159, 366-374. [CrossRef]

57. Sadhukhan, S.; Ghosh, T.K.; Roy, I.; Rana, D.; Bhattacharyya, A.; Saha, R.; Chattopadhyay, S.; Khatua, S.; Acharya, K.; Chattopadhyay, D. Green synthesis of cadmium oxide decorated reduced graphene oxide nanocomposites and its electrical and antibacterial properties. Mater. Sci. Eng. C Mater. Biol. Appl. 2019, 99, 696-709. [CrossRef] [PubMed] 